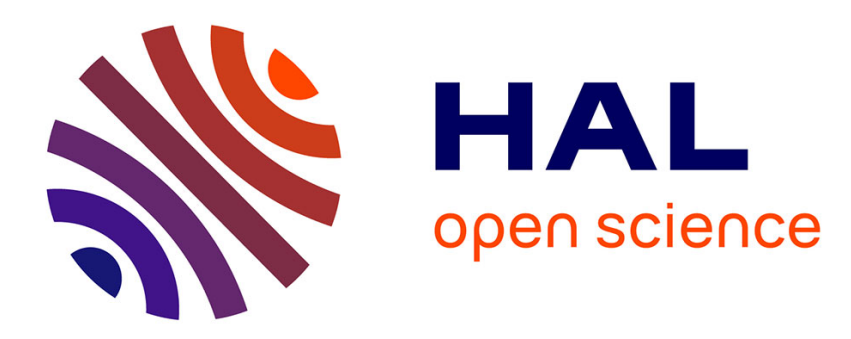

\title{
Ultrasonic attenuation in glassy crystalline cyclohexanol
}

M. Saint Paul, R. Nava

\section{To cite this version:}

M. Saint Paul, R. Nava. Ultrasonic attenuation in glassy crystalline cyclohexanol. Journal de Physique Lettres, 1983, 44 (14), pp.613-617. 10.1051/jphyslet:019830044014061300 . jpa-00232239

\section{HAL Id: jpa-00232239 https://hal.science/jpa-00232239}

Submitted on 1 Jan 1983

HAL is a multi-disciplinary open access archive for the deposit and dissemination of scientific research documents, whether they are published or not. The documents may come from teaching and research institutions in France or abroad, or from public or private research centers.
L'archive ouverte pluridisciplinaire HAL, est destinée au dépôt et à la diffusion de documents scientifiques de niveau recherche, publiés ou non, émanant des établissements d'enseignement et de recherche français ou étrangers, des laboratoires publics ou privés. 
Classification

Physics Abstracts

$61: 40-62.80 \mathrm{~F}$

\title{
Ultrasonic attenuation in glassy crystalline cyclohexanol (*)
}

\author{
M. Saint Paul and R. Nava \\ Instituto Venezolano de Investigaciones Científicas, \\ Centro de Física, Apartado 1827, Caracas 1010A, Venezuela
}

(Reçu le 25 avril 1983, accepté le 27 mai 1983)

\begin{abstract}
Résumé. - On rapporte des mesures d'atténuation ultrasonore à $100 \mathrm{MHz}$ sur la phase réorientationnelle du cyclohexanol. Les résultats confirment qu'au refroidissement le désordre orientationnel des molécules dans le réseau cristallin est gelé progressivement en suịvant un mécanisme de relaxation.

Abstract. - Ultrasonic attenuation measurements at $100 \mathrm{MHz}$ on the orientationally disordered crystalline phase of cyclohexanol are reported. The results provide additional evidence that the freezing process of the orientational disorder of the molecules in the crystal lattice is a relaxational phenomenon.
\end{abstract}

\section{Introduction.}

It is well known that cyclohexanol belongs to the group of organic compounds which exhibit an orientationally disordered phase immediately below their melting point $[1,2]$. This crystalline phase is characterized by rapid rotational motions of molecules and is known to be plastic according to Timmermans' criterion [1]. Furthermore, the orientationally disordered or plastic crystals can be supercooled into a glass-like_state $[3,4]$.

Previous studies of cyclohexanol [5] show that the higher temperature plastic phase (phase I) is stable between 265 and $298 \mathrm{~K}$ and it is easily supercooled. A moderate cooling rate of $6 \mathrm{~K} / \mathrm{min}$. is sufficient to prevent the transformation into the stable phase. II. The supercooled phase I shows some characteristic features of the glass transition : a discontinuous specific heat at the glass transition temperature $T_{\mathrm{g}}$ of $150 \mathrm{~K}$ and a residual entropy at $0 \mathrm{~K}$. Slow relaxation processes covering a wide frequency range, from $10^{-3}$ to $10^{5} \mathrm{~Hz}$, are responsible for the reported dielectric relaxations $[6,8]$. Motional narrowing effects observed around $T_{\mathrm{g}}$ in nuclear magnetic resonance experiments $[7,8]$ show that the molecular reorientations become progressively slower when the temperature is decreased below $T_{\boldsymbol{g}}$. At low temperatures some properties similar to those found in ordinary glasses have been observed in this rotational glass [10]. In order to better describe the freezing process of the molecular reorientations and their importance at low temperatures we have studied the ultrasonic loss in the disordered phase I of cyclohexanol above liquid helium temperatures.

(*) Work supported by the Consejo National de Investigaciones Científicas y Tecnológicas (CONICIT) under grant No SI-1050. 


\section{Experimental.}

Ultrasonic measurements were performed between 60 and $200 \mathrm{MHz}$ on samples of cyclohexanol of commercial purity (Baker Co.). Because of the high ultrasonic attenuation of liquid cyclohexanol the attenuation measurements had to be performed on very thin specimens using the bufferrod method described in [11]. The inset of figure 1 shows a schematic illustration of the sample mounting. A film of liquid cyclohexanol (C) was placed at room temperature between two Z-cut quartz delay rods (Q) of dimensions $4 \times 4 \times 25.4 \mathrm{~mm}^{3}$ and $4 \times 4 \times 12.5 \mathrm{~mm}^{3}$ with optically polished and parallel end faces. The two rods were separated by a thin copper ring spacer (S) of calibrated thickness. The whole assembly was placed inside the channel of a brass sample holder (Sa) and good thermal contact was established by means of copper-beryllium springs. The temperature was determined by means of calibrated thermocouples and carbon resistors (T) firmly attached to the sample holder. Longitudinal ultrasonic waves were generated and detected by means of a polyvinylidene fluoride $\left(\mathrm{PVF}_{2}\right)$ transducer bonded with flexible adhesive $(\mathrm{Ox}$ ford Instruments) to the longer delay rod. Using a standard pulse-echo technique the detected echo pattern consists of two distinct trains associated with the delay paths of the elastic waves in the rod-sample assembly:

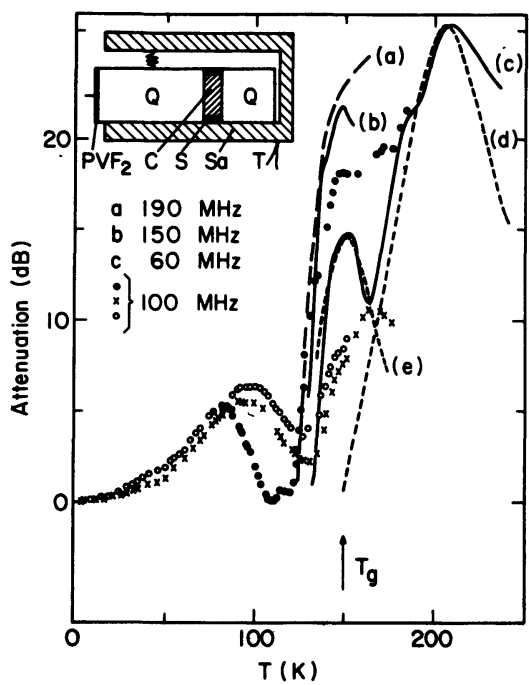

Fig. 1. - Attenuation $E_{\mathrm{R}} / E_{\mathrm{T}}$ in $\mathrm{dB}$ as a function of temperature for four samples of cyclohexanol $(0 \mathrm{~dB}$ corresponds to the values measured at $4 \mathrm{~K})$. The experimental curves $(a),(b),(c)$ and the filled circles were taken during cooling from 300 to $100 \mathrm{~K}$ at a rate of $6 \mathrm{~K} / \mathrm{min}$. Circles and crosses correspond to measurements on the same sample : - during supercooling to $80 \mathrm{~K}$ (run 1), 0 subsequently heated from $4 \mathrm{~K}$ at a rate of $0.8 \mathrm{~K} / \mathrm{min}$. (run 2), $\times$ after further heat treatment and annealing (see text), during heating at $0.8 \mathrm{~K} / \mathrm{min}$. (run 3). The dashed curves $(e)$ and $(d)$ are calculated from equation 4 with activation energies of 1500 and $1560 \mathrm{~K}$ and $\tau_{0}$ of 1 and $13 \times 10^{-13} \mathrm{~s}$, respectively. The inset shows the experimental arrangement for the buffer-rod technique described in the text.

The first detected echo of amplitude $E_{\mathrm{R}}$ corresponds to the reflection from the long quartzcyclohexanol interface. The second detected echo, associated with the reflection from the free end surface of the short quartz, has its magnitude $E_{\mathrm{T}}$ considerably attenuated by its double path in the cyclohexanol film. By comparing the amplitude ratio $E_{\mathrm{R}} / E_{\mathrm{T}}$ for films of different thicknesses 
$d$ or for different frequencies the intrinsic attenuation coefficient $\alpha$ of cyclohexanol can in principle be determined from

$$
E_{\mathrm{R}} / E_{\mathrm{T}}=Z\left(\mathrm{e}^{2 \gamma d}-1\right)
$$

where $Z=r /\left(1-r^{2}\right)^{2}, r$ is the reflection coefficient of the quartz-cyclohexanol interface, assumed here to be constant, and $\gamma=\alpha+i \phi$ is the complex propagation constant in the film with the phase constant $\phi$ given by

$$
\phi=2 \pi F d / v,
$$

here $F$ is the frequency and $v$ is the sound velocity in cyclohexanol. Equation 1, where the relatively small attenuation of the quartz rods has been neglected, contains multiple-beam interference terms which occur when the film thickness becomes comparable to the sound wavelength and which would produce oscillations in $E_{\mathrm{R}} / E_{\mathrm{T}}$ with frequency or film thickness making a direct determination of $\alpha$ difficult. We find, however, that since $\alpha d$ is small in the liquid phase [12] expanding $\operatorname{Ln}\left(E_{\mathrm{R}} / E_{\mathrm{T}}\right)$ in powers of $\alpha d$ gives

$$
\operatorname{Ln}\left(E_{\mathrm{R}} / E_{\mathrm{T}}\right)=2 \alpha d+(\alpha d)^{2} O(\phi)+P(\mathrm{Z}, \phi)
$$

where $P=2 \operatorname{Ln}(2 Z \sin \phi)$ is nearly independent of $T$ and the second term is less than $10 \%$ of the first for liquid film of $40 \mu \mathrm{m}$ and $F \lesssim 100 \mathrm{MHz}$ (it is about $20 \%$ and $35 \%$ for 150 and $190 \mathrm{MHz}$, respectively). Thus for the lower experimental frequencies $\operatorname{Ln}\left(E_{\mathrm{R}} / E_{\mathrm{T}}\right)$ reflects reasonably well the temperature dependence of the attenuation coefficient. This approximation becomes better as the temperature (and the attenuation in the solid phases) is decreased. Furthermore, by normalizing the measured attenuation for different frequencies to its value at $4 \mathrm{~K}$ (corresponding to $0 \mathrm{~dB}$ in Fig. 1) we suppress the effect of the oscillating term $P$ on the temperature dependence of $\alpha$.

Measurements of the amplitude ratio $E_{\mathrm{R}} / E_{\mathrm{T}}$ in decibels, which we call here the attenuation, were performed with a Matec 2470 Automatic Attenuation Recorder. An intrinsic attenuation coefficient of $188 \mathrm{~dB} / \mathrm{cm}$ was deduced for liquid samples at $300 \mathrm{~K}$ from measurements in three films 80,130 and $160 \mu \mathrm{m}$ thick at $60 \mathrm{MHz}$. This value is in good agreement with the results reported by Plass [12]. From measurements as a function of frequency in $80 \mu \mathrm{m}$-thick films at $77 \mathrm{~K}$ we found that the attenuation oscillates with a frequency of approximately $20 \mathrm{MHz}$. This provides, through equation 2 an estimate of $3 \times 10^{5} \mathrm{~cm} / \mathrm{s}$ for the longitudinal sound velocity in solid cyclohexanol.

All solid cyclohexanol samples were prepared by cooling the liquid films in a helium atmosphere from 300 to $100 \mathrm{~K}$ at a rate of $6 \mathrm{~K} / \mathrm{min}$. and from 100 to $80 \mathrm{~K}$ at a slower rate of $1 \mathrm{~K} / \mathrm{min}$. The samples were subsequently cooled to $4 \mathrm{~K}$. Attenuation measurements as a function of temperature were possible and reproducible for different frequencies for solid films about $80 \mu \mathrm{m}$ thick by recording the amplitude ratio $E_{\mathrm{R}} / E_{\mathrm{T}}$ in $\mathrm{dB}$ as the temperature was changed. Various attempts with solid films thicker than $100 \mu \mathrm{m}$ were unsuccessful due to a drastic deterioration of the echo pattern as the temperature was decreased. For all reported frequencies the temperature dependence of the attenuation was measured during the (super) cooling cycle to $80 \mathrm{~K}$ at the rates given above. In order to characterize the low temperature contribution to the attenuation due to the orientational disorder different cycles of measurements at each frequency were performed from $4 \mathrm{~K}$ to about $150 \mathrm{~K}$ on the same samples supercooled firstly below $T_{\mathrm{g}}$ and then annealed at $160 \mathrm{~K}$.

The sequence of measurement followed is illustrated in figure 1 by the data taken at $100 \mathrm{MHz}$. (Run 1) first the data (full circles) were taken upon supercooling to $80 \mathrm{~K}$ at the rates given above. (Run 2) then the measurements (open circles) were taken on the supercooled sample from $4 \mathrm{~K}$ to $160 \mathrm{~K}$ at a heating rate of $0.8 \mathrm{~K} / \mathrm{min}$. (Run 3) the sample was then cooled down to $80 \mathrm{~K}$ in about 10 hours and subsequently cooled to $4 \mathrm{~K}$, and finally the data (crosses) were taken from $4 \mathrm{~K}$ to $180 \mathrm{~K}$ at the same heating rate of $0.8 \mathrm{~K} / \mathrm{min}$. 


\section{Results.}

Figure 1 shows the experimental attenuation in cyclohexanol as a function of temperature for four samples and four different frequencies (run 1). For clarity the experimental results for slow heating (run 2) and after sample annealing (run 3) are shown only at $100 \mathrm{MHz}$, but the same general features were observed at all frequencies.

Upon fast cooling (run 1) the attenuation of the supercooled phase I shows two different temperature regimes :

(i) a high temperature regime occurring above the characteristic temperature $T_{\mathrm{g}}=150 \mathrm{~K}$ in which the attenuation of the supercooled phase $\mathrm{I}$ is very high. Around $200 \mathrm{~K}$ its magnitude measured at $60 \mathrm{MHz}$ is comparable to that found for the liquid at $300 \mathrm{~K}$ and too high to be measured at higher frequencies. Two maxima centred at $150 \mathrm{~K}$ and $210 \mathrm{~K}$ are observed at $60 \mathrm{MHz}$, and at all frequencies the attenuation decreases very rapidly below $T_{\mathrm{g}}$. From measurements performed at $15 \mathrm{MHz}$ we observed the same behaviour around $T_{\mathrm{g}}$. The $150 \mathrm{~K}$ peak is well resolved but the experimental conditions were not as good as at $60 \mathrm{MHz}$ and did not permit to extend measurements above $190 \mathrm{~K}$. For clarity the results taken at this frequency are not shown in figure 1 .

(ii) a low temperature regime occurring below $T_{\mathrm{g}}$ in which the attenuation shows a broad peak centred around $80 \mathrm{~K}$ and has a small magnitude. This regime is only shown for $100 \mathrm{MHz}$ in figure 1 and corresponds to full circles below $120 \mathrm{~K}$ and open circles below $80 \mathrm{~K}$.

Upon slow heating from $4 \mathrm{~K}$ the attenuation $v$ s. temperature curves are very similar for both the unannealed (run 2) and annealed (run 3) samples but are somewhat different above $100 \mathrm{~K}$ from those obtained during supercooling (run 1). In neither case does the attenuation recover its value in the supercooling cycle, the difference at $100 \mathrm{MHz}$ being as large as $10 \mathrm{~dB}$.

In all annealing treatments we observe that the echo train transmitted through the cyclohexanol film is lost when the temperature increases above $190 \mathrm{~K}$ and it is not recovered when the temperature is again decreased. This is probably due to cracks produced in the film by differential thermal stresses and seems to indicate that the plasticity of the film is reduced by slow heating. As a consequence it has not been possible to study the acoustic properties after thermal annealing above $200 \mathrm{~K}$.

The most remarkable conclusion of our results is that there is a continuous decrease of the ultrasonic attenuation of the supercooled phase $I$ of the cyclohexanol as the temperature is reduced through the characteristic temperature $T_{\mathrm{g}}$ where a discontinuity in the specific heat has been observed $[5,8]$. The experimental results indicate that, for rapidly cooled samples, the behaviour of the ultrasonic attenuation above $T_{\mathrm{g}}$ must be associated with the dynamic disorder of the molecules in the supercooled phase I and that a gradual freezing of the molecular motions occur when temperature decreases below $T_{\mathrm{g}}$. The results of figure 1 cover a small frequency range but nevertheless information on the relaxation process which governs the freezing of the reorientational disorder in phase I may be obtained. The peak observed at $210 \mathrm{~K}$ for $60 \mathrm{MHz}$ is well resolved and can be reasonably described by a Debye relaxation

$$
A \sim \frac{\omega^{2} \tau_{1}}{1+\left(\omega \tau_{1}\right)^{2}}
$$

where $\omega$ is the angular ultrasonic frequency and $\tau_{1}$ is the relaxation time $\tau_{1}=1.3 \times 10^{-12}$ $\exp (1560 / T)$ (s) deduced from NMR experiments [7]. The peak at $150 \mathrm{~K}$, observed at $60 \mathrm{MHz}$, is not as well resolved at higher frequencies. The attenuation around $T_{\mathrm{g}}$ increases with frequency but not linearly. As discussed above the phase terms in expression 3 become important corrections at high frequencies and temperatures and the measured temperature dependence of the attenuation around $T_{\mathrm{g}}$ is only qualitatively related to that of $\alpha$. The activation energy of the $150 \mathrm{~K}$ relaxation peak cannot be directly extracted from our results because of the limited frequency 
where it is well resolved. Nevertheless, the experimental results can be roughly fitted at $60 \mathrm{MHz}$ by a Debye curve and a relaxation time $\tau_{2}$ with an activation energy of $1500 \mathrm{~K}$ and a pre-exponential factor of $10^{-13} \mathrm{~s}$ (curve $e$ in Fig. 1). This should only be taken as a qualitative indication. The drastic decrease of the attenuation observed for all frequencies below $T_{\mathrm{g}}$ may be indicative that we are entering a regime where $\omega \tau_{2}$ becomes greater than one.

Finally, we comment on the ultrasonic attenuation of the thermally treated cyclohexanol films. It is well known that thermal annealing above $200 \mathrm{~K}$ causes the transformation of the supercooled phase I of the cyclohexanol into the ordered phase II [5]. Transformations into different metastable crystalline phases have also been observed below $200 \mathrm{~K}$ by differential thermal analysis measurements on bulk samples [5]. It has also been pointed out that between 170 and $200 \mathrm{~K}$ the supercooled phase I tends to recrystallize into phase II [7, 8]. In the light of these observations and due to the difficulties we encounter when measuring the ultrasonic attenuation after a thermal annealing above $200 \mathrm{~K}$, because of the mechanical failure of the cyclohexanol film, it is undetermined whether our samples annealed to about $160 \mathrm{~K}$ were in a metastable mixed crystalline phase or in the stable phase II. However, we note that below $80 \mathrm{~K}$ the temperature dependence of the attenuation in the disordered phase I (open circle in Fig. 1) is quite similar to that observed after thermal treatment at $160 \mathrm{~K}$ (crosses in Fig. 1).

\section{Conclusions.}

The present ultrasonic results give evidences that the freezing process occurring in the supercooled plastic phase of cyclohexanol is a relaxational phenomenon. An activation energy corresponding to $1560 \mathrm{~K}$ in good agreement with the value previously deduced from NMR experiments has been obtained. No additional ultrasonic losses with respect to those found in the phase annealed around $160 \mathrm{~K}$ have been observed in the orientationally disordered phase at liquid helium temperatures.

\section{References}

[1] Timmermans, J., J. Phys. Chem. Solids 18 (1961) 1.

[2] Johari, G. P. and Chan, R. K., Can. J. Chem. Educ. 10 (1975) 8, 10.

[3] SugA, H. and SeKi, S., J. Non-Cryst. Solids 16 (1974) 171.

[4] Johari, G. P., Philos. Mag. B 41 (1980) 41 ; and in The Glass Transition and the Nature of the Glassy State, eds. M. Goldstein and R. Simha Ann. New York Acad. Sci. 279 (1976) 117.

[5] AdaChi, K., SugA, H. and SeKi, S., Bull. Chem. Soc. Jpn 41 (1968) 1073.

[6] Adachi, K., Suga, H., Seki, S., Kubota, S., Yamaguchi, S., Yano, O. and Wada, Y., Mol. Cryst. Liq. Cryst. 18 (1972) 345.

[7] Eguchi, T., SOdA, G. and ChiHARA, H., J. Magn. Reson. 23 (1975) 55.

[8] Dworkin, A., Fuchs, A. H., Ghelfenstein, M. and Szwarc, H., J. Physique Lett. 43 (1982) L-21.

[9] Ceccaldi, D., Denoyer, F., Lambert, M. and Szwarc, H., J. Physique Lett. 41 (1980) L-365.

[10] Bonjour, E., Calemczuk, R., Lagnier, R. and Salce, B., J. Physique Colloq. 42 (1981) C6-63.

[11] McSkimin, H. J., in Physical Acoustics ed. W. P. Mason, vol. IA (Academic Press) 1964, page 271.

[12] Plass, K. G., Acustica 19 (1967/68) 236. 